\title{
Histopathological Spectrum of Uterus and Cervix in Hysterectomy Specimens
}

\author{
Ankur Gupta ${ }^{1^{*}}$, Sangita Sehgal ${ }^{2}$, Ajay yadav³ ${ }^{3}$ Vinod Kumar ${ }^{4}$ \\ ${ }^{1 *}$ Resident, ${ }^{2}$ Associate Professor, ${ }^{3}$ Professor \& Head, Department of Pathology, SMS Medical College, Jaipur, Rajasthan, India. \\ ${ }^{4}$ Assistant Professor, Department of Community Medicine, Jhalawar Medical College, Jhalawar, Rajasthan, India.
}

\begin{abstract}
Background: Hysterectomy is considered definite treatment of various pelvic pathologies like leiomyoma, dysfunctional uterine bleeding (DUB), chronic pelvic pain, endometriosis, adenomyosis, prolapse, and malignancies, since early twentieth century. In fact, it is the second most frequently performed major surgical procedure in females all over the world next to cesarean section.Numerous types of nonneoplastic and neoplastic lesions of uterus and cervix are commonly encountered in clinical practice. The present study is aimed at a detailed histopathological evaluation of all lesions of hysterectomy specimens in a tertiary care hospital of Rajasthan over the period of January 2014 to December 2015. Material \& Methods: A Laboratory based descriptive type of observational study done in Department of Pathology, S.M.S Medical College, Jaipur from January 2014 to December 2015. We included 400 hysterectomy specimens' uterus and cervix, All specimens after fixation in $10 \%$ buffered formalin, processed and then stained with Hematoxylin \& Eosin to study various histopathological patterns.

Results: The commonest type of hysterectomy was Total abdominal hysterectomy with bilateral Salpingo-oophorectomy with 217 cases (54.25\%) and the commonest clinical indication being Fibroid uterus in $164(41 \%)$ cases. The peak age of incidence of hysterectomy was noted in the 5 th decade with 186 cases $(46.5 \%)$. The commonest lesion encountered was
\end{abstract}

\section{INTRODUCTION}

The Female Genital Tract is a hormone responsive system to a degree unmatched by another system in the human body. The gross configuration of uterus changes dramatically throughout life. It is a kind of "Puppet on a string", thus manipulated throughout life by changing levels of ovarian hormones. Cyclic uterine bleeding, which begins in the anatomically and physiologically normal female, marks an important stage of reproductive maturation. The endometrium is an endocrine organ that responds to circulating blood levels of estrogen and progesterone. 1-3 $^{-3}$

Since the uterus is constantly under the influence of hormones, the histology as well as the pathological lesions shows a wide variation. Hysterectomy is performed either vaginal or abdominal. The present study was aimed at a detailed histopathological evaluation of all lesions of hysterectomy specimens. Hysterectomy is the most common major operation performed in gynaecological practice and it provides an adequate evaluation of endometrium. It produces an intact uterus and consequent control over tissue sampling and hence enabling determination of the origin of a particular lesion. $^{3}$ leiomyoma in 225 cases (54.3\%), 4 cases $(2.9 \%)$ of carcinoma endometrium, 10 cases $(2.5 \%)$ of carcinoma cervix and 1 case $(0.2 \%)$ of cervical dysplasia were encountered. Two different rare and interesting lesions were encountered in the Present study such as 1 case $(0.2 \%)$ of low-grade endometrial stromal sarcoma, 1 case $(0.2 \%)$ of Benign Cellular Leiomyoma.

Conclusion: Histopathological study of uterine and cervix lesions is mandatory in establishing the final diagnosis.

KEYWORDS: Benign lesion, Histopathology, Malignant lesion, Non-Neoplastic, Uterus.

\section{${ }^{*}$ Correspondence to:}

Dr. Ankur Gupta, E 132, Sector 2, Chitrakoot yojna, Vaishali nagar, Jaipur, Rajasthan.

Email: draaankur.100@gmail.com

\begin{tabular}{l} 
Article History: \\
Received: 03-05-2016, Revised: $10-05-2016$, Accepted: 27-05-2016 \\
\begin{tabular}{|l|c|}
\hline \multicolumn{2}{|c|}{ Access this article online } \\
\hline $\begin{array}{l}\text { Website: } \\
\text { www.jimrp.com }\end{array}$ & Quick Response code \\
\hline DOl: & \\
10.21276/ijmrp.2016.2.3.029 &
\end{tabular} \\
\hline
\end{tabular}

\section{AIMS \& OBJECTIVES}

- To study the gross and histopathological findings in hysterectomy specimens and to correlate with the clinical diagnosis.

- To analyse the distribution of histopathological findings in various age groups.

- To study the various associated and incidental organic pathological lesions in the hysterectomy specimens.

\section{MATERIAL AND METHODS}

This is a prospective study of 400 cases, conducted in the Department of Pathology of Sawai Man Singh Medical College and Hospital, for the period of January 2014 to December 2015. Demographic data regarding age, sex, chief complaints, clinical examination and radiological investigations was retrieved from histopathology and OPD records.

Hysterectomy samples were fixed in $10 \%$ formalin and histopathological slides were prepared and Hematoxylin \& Eosin staining was done and wherever needed special stains like Periodic Acid Schiff and Mucicarmine stain etc. were applied. 
Then after gross examination and Histopathological examination under microscope various data were noted and recorded for analysis.

The lesions were differentiated in non-neoplastic and neoplastic lesions. Data was entered in Microsoft office excel and tables were prepared and analysed in the form of proportion and percentage.

\section{RESULTS}

The Present study is aimed at the morphological evaluation of lesions of uterus and cervix in 400 hysterectomy specimens, in approximately 2-year duration.

1. The specimens were obtained from the patients attending and undergoing hysterectomy operation at Gangori, Zenana and Mahila Chikitsalaya (Hospitals attached to the SMS medical college and hospitals).

2. The commonest route of hysterectomy was abdominal and commonest type of hysterectomy performed during this study was Total abdominal hysterectomy with bilateral Salpingooophorectomy with 217 cases (54.25\%) and the commonest clinical indication being Fibroid uterus in 164 (41\%) cases.

3. The peak age incidence of hysterectomy was noted in the 5th decade with 186 cases (46.5\%). The youngest patient was aged 24years and the oldest patient was aged 70 years.

4. The clinical indications for the hysterectomies were analyzed, the most common causes included Fibroid uterus 164 cases (41\%), DUB-142 cases (35.5\%), Prolapsed uterus 42 cases $(10.5 \%)$, and the less common included Polyp uterus 8 cases (2\%), Fibroid polyp 2 cases (0.5\%), Cervical polyp 3 cases $(0.75 \%)$, Cervical dysplasia 5 case $(1.25 \%)$, Carcinoma Cervix 6 cases $(1.5 \%)$, and Carcinoma Uterus 9 cases $(2.25 \%)$.

5. The histopathological findings were analysed.

- The Endometrial findings encountered were: Proliferative pattern in 234 cases (58.5\%), Secretory pattern in 98 cases (24.5\%), Atrophic pattern in 6 cases (1.5\%), Simple hyperplasia in 16 cases $(2.9 \%)$, Endometritis in 6 cases $(1.5 \%)$, Endometrial polyp in 21 cases $(5.25 \%)$, Simple hyperplasia of endometrium in 16 case $(0.4 \%)$, and Adenocarcinoma of endometrium in 9 cases (2.25\%).

Grossly, of the 9 cases of carcinoma endometrium, 5 cases $(55.6 \%)$ were protruding and 4 cases $(44.4 \%)$ were Infiltrative grossly. Microscopically, 2 cases were well- differentiated adenocarcinoma of endometrium -grade I, 2 cases were endometrioid adenocarcinoma of the endometrium with squamous and secretory differentiation, 2 cases were of moderately differentiated adenocarcinoma of the endometrium, 2cases were of well-differentiated adenocarcinoma of the endometrium and 1 case each of endometrioid adenocarcinoma of endometrium grade II \& III.

- The Myometrial findings were: Leiomyomal Leiomyomatous polyp in 225 cases (54.3\%), Adenomyosis in 95 cases $(23.7 \%)$, Adenomyoma in 1 case $(0.2 \%)$, and Endometrial Stromal Sarcoma in 1 case $(0.7 \%)$.

Grossly, 168 (74.67\%) Leiomyomas were solitary and 57 $(25.33 \%)$ were multiple. Among the types of leiomyoma, Intramural Leiomyomas were the commonest in 169 cases $(75.1 \%)$, followed by Mixed in 29 cases $(12.9 \%)$, Sub serosal in 14 cases (6.2\%) and Sub mucosal in 13 cases $(5.8 \%)$. Of the total 225 cases of Leiomyoma, 5 cases $(1.25 \%)$ showed secondary changes such as mucoid/myxoid degeneration and hyaline change. Of the variants of Leiomyoma, 1 case showed Epithelioid type and 1 case showed benign cellular Leiomyoma.

- The Cervical findings encountered were: The cervical findings encountered were Chronic Non-Specific Cervicitis in 380 cases $(95 \%)$, nabothian cysts in 92 cases $(23 \%)$, Chronic Polypoidal Endo Cervicitis in 6 cases (1.5\%), Leiomyoma cervix/ leiomyomatous cervical polyp in 6 cases $(1.5 \%)$, decubitus ulcer in 2 cases $(0.5 \%), 1$ case $(0.2 \%)$ of cervical dysplasia, and 7 cases $(1.75 \%)$ of SCC of cervix.

Grossly, of the 10 cases of carcinoma cervix, 5 cases (50\%) were endophytic and 5 cases (50\%) were exophytic in our study. Microscopically, 4 cases were Large cell keratinizing Squamous Cell Carcinoma of the cervix,2 cases were moderately differentiated squamous cell carcinoma of the cervix, 2 cases were large cell Non-keratinizing Squamous Cell Carcinoma of the cervix, 1 case was Cervical Adenocarcinoma of usual type and 1 case was Invasive squamous cell carcinoma.

6. Rarest and interesting lesions encountered were 1 case $(0.7 \%)$ of Low-Grade Endometrial Stromal Sarcoma, 1 case of Benign Cellular Leiomyoma.

7. In 52 cases of hysterectomy specimens examined no pathological lesion was encountered.

Table 1: Distribution according to type of Hysterectomy in the study group

\begin{tabular}{clcc}
\hline Sl. No. & Type of Hysterectomy & No. of cases & Percentage (\%) \\
\hline $\mathbf{1}$ & Total Abdominal Hysterectomy & 140 & 35 \\
$\mathbf{2}$ & Total Abdominal Hysterectomy+Unilateral Salpingo Oophorectomy & 36 & 9 \\
$\mathbf{3}$ & Total Abdominal Hysterectomy + Left Ovary & 1 & 0.25 \\
$\mathbf{4}$ & Total Abdominal Hysterectomy + Unilateral Salpingo & 1 & 0.25 \\
& Oophorectomy+ Left Fallopian Tube & & \\
$\mathbf{5}$ & Total Abdominal Hysterectomy +Bilateral Salpingo Oophorectomy & 217 & 54.25 \\
$\mathbf{6}$ & Total Abdominal Hysterectomy + Right Ovary & 1 & 0.25 \\
7 & Vaginal Hysterectomy & 4 & 1 \\
TOTAL & & 400 & 100 \\
\hline
\end{tabular}


Table 2: Shows the Clinical indication for hysterectomy in the study group

\begin{tabular}{clcc}
\hline SI. No. & Clinical Indication & No. of Cases & Percentage (\%) \\
\hline $\mathbf{1}$ & Fibroid Uterus & 164 & 41 \\
$\mathbf{2}$ & DUB & 142 & 35.5 \\
$\mathbf{3}$ & Prolapsed Uterus & 42 & 10.5 \\
$\mathbf{4}$ & Polyp Uterus & 8 & 2 \\
$\mathbf{5}$ & Fibroid Polyp & 2 & 0.5 \\
$\mathbf{6}$ & Cervical Dysplasia & 5 & 1.25 \\
$\mathbf{7}$ & Carcinoma Cervix & 6 & 1.5 \\
$\mathbf{8}$ & Carcinoma Uterus & 9 & 2.25 \\
$\mathbf{9}$ & Cervical Polyp & 3 & 0.75 \\
$\mathbf{1 0}$ & No diagnosis offered & 19 & 4.75 \\
& TOTAL & 400 & 100 \\
\hline
\end{tabular}

Table 3: Incidence of Histopathological findings for 400 Cases

\begin{tabular}{clcc}
\hline SI.No. & \multicolumn{1}{c}{ Histopathological Findings } & No. of cases & Percentage (\%) \\
\hline 1 & No significant lesions in endometrium (PP, SP, AP) & 302 & 75.5 \\
2 & CGH & 10 & 02.5 \\
3 & Endometritis & 06 & 01.5 \\
4 & Endometrial polyp & 21 & 05.25 \\
$\mathbf{5}$ & Leiomyoma/ Leiomyomatous Polyp & 225 & 56.2 \\
$\mathbf{6}$ & Adenomyosis & 95 & 23.7 \\
$\mathbf{7}$ & Medial Calcific Sclerosis & 01 & 00.2 \\
$\mathbf{8}$ & Atypical hyperplasia of endometrium & 01 & 00.2 \\
9 & Adenomyoma & 01 & 00.2 \\
10 & Adenocarcinoma of Endometrium & 09 & 02.25 \\
11 & Endomeetrial Stromal Sarcoma & 01 & 00.2 \\
12 & Chronic Non Specific Cervicitis & 380 & 95.0 \\
13 & Chronic Polypoidal Endo Cervicitis & 02 & 0.5 \\
14 & Nabohian Cyst & 92 & 23.0 \\
15 & Cervical polyp(Leiomyomatous) & 06 & 01.5 \\
16 & Cervical dysplasia & 01 & 00.2 \\
17 & Decubitus ulcer & 02 & 00.5 \\
18 & Endocervical polyp & 02 & 00.5 \\
19 & Carcinoma Cervix & 10 & 2.5 \\
\hline
\end{tabular}

\section{DISCUSSION}

Hysterectomy is the most commonly performed major gynaecological surgery throughout the world. It is a successful operation in terms of symptom relief and patient satisfaction and provides definitive cure to many diseases involving uterus as well as adnexa.

This study was conducted to analyse the patterns of lesions in hysterectomy specimens in our institution and to compare our findings with those of other workers

In our study, the incidence of abdominal hysterectomy was higher (396cases-99\%) than the vaginal (4cases-1\%), as in the studies done by Sunita Malik et al (1992) 4 series, abdominal constituted $80.6 \%$ and vaginal $19.4 \%$.

In the Present study, the age ranged from 21-70 years with a mean age of 44.24 years. In the Priya Bhide et al (1994)5 series, the age range was 28-58 years with a mean of 37.3 years and in Gautam Allahbadia et al (1991)6 series, the age range was 30-69 years with a mean age of 35 years.

The peak age incidence of hysterectomy was in the 5 th decade in the Present study. The study done by Kasturi Lal et al (1981)7 and Ajmera Sachin K et al (2006)8 had similar findings.
The most common clinical indication for hysterectomy in the Present study was uterine fibroid in 164 cases (41\%). Similar findings were observed in the Ajmera Sachin K et al8 series in 170 cases (48.6\%) and Stewart and Arti9 series in 33 cases (33\%).

The incidence of Endometrial Polyps varied in different studies. In the Present study, it was $5.25 \%$, whereas in Veena S. Naik et al 10 series, it was $2.88 \%$ and in Priya Bhide et al5 series, it was $2.34 \%$.

The incidence of adenomyosis was $23.7 \%$ in the Present study. The incidence was $15 \%, 12.7 \%, 21 \%$, and $19 \%$ in the Kasturi Lal et al7 series, Roopam Kalra et al11 series, Sunita Malik et al4 series and Priya Bhide et al5 series respectively. According to Roopam Kalra et al11 the incidence of adenomyosis varies from $6-40 \%$ the incidence in the present study falls in the above range. The incidence of leiomyoma was $5.4-77 \%$ according to Henry Annan et al (2005)12 and 5-80\%, according to Gavin F. Jacobson et al (2007)13. The incidence in the Present study was $56.3 \%$. In Stewart \& Arti et al series (1990)9, the incidence was $52 \%$ which is comparable to the Present study (56.2\%).

In the Present study, the incidence of carcinoma endometrium was 9 cases $(2.25 \%)$ of the total 400 cases. In the John J. Molitor 
(1971)14 series, it was 4 cases (1.42) of the total 281 cases, in Veena S. Naik et al (2005)10 series, it was 10 cases $(9.61 \%)$ of the total 108 cases and in Ehsan Ullah et al series it was 13 cases $(1.38 \%)$ of the total 400 cases.

The incidence of carcinoma cervix in the Present study was 10 cases $(2.5 \%)$ of the total 400 cases. Low incidence was noted in the M. L. Solapurkar (1985)15 series with 2 cases $(0.36 \%)$ of the total 551 cases and a high incidence was noted in the Kasturi Lal et al (1981)7 series with 3 cases $(8.57 \%)$ of 35 cases. The Present study was comparable to that of Gautam Allahbadia et al (1991)6 with 3 cases (3\%) of 100 cases.

In the Present study, 1 case $(0.25 \%)$ of rare and interesting lesion of Low-grade endometrial stromal sarcoma was encountered. The patient was aged 42 years, presented with bleeding per vaginum, with a clinical diagnosis of the fibroid. Grossly, it was a poorly defined gray-yellow mass in the myometrium measuring $4 \times 3.5 \mathrm{~cm}$. Cervix was uninvolved.

Nalini Gupta et al (2007)16 reported a case of low-grade endometrial stromal sarcoma in a 23 years old patient, who presented with bleeding per vaginum and grossly, it appeared as a polypoid mass measuring $14 \times 13 \times 5 \mathrm{~cm}$.

\section{CONCLUSION}

Uterine fibroids and adenomyosis are the most common benign conditions found in hysterectomy specimens with the peak incidence at 41-50 years. Histopathology is mandatory for confirming the diagnosis. The present study highlights the spectrum of lesions of the uterus and cervix which is further divided into various categories. These categories can provide the basis for identifying the etiology. The spectrum of uterus and cervical lesions is vast and therefore early detection and management of certain lesions can help in reducing the morbidity. The Present study correlates with other studies in India and Abroad.

\section{RECOMMENDATIONS}

When hysterectomy specimens are subjected to histopathological examination wide range of lesions is encountered. Few lesions are also encountered as pure incidental findings, though the histopathological analysis correlates well with the clinical diagnoses. Hence, it is mandatory to do a detailed histopathological examination of every hysterectomy specimen, even if it grossly appears to be normal, as to ensure diagnosis and thus a better postoperative management.

Histopathology is considered as a gold standard in diagnosing the lesions of the female genital tract. However, even after microscopic examination many lesions are mistakenly over diagnosed to be neoplastic. So, the help of further studies must be taken up to evaluate these nonneoplastic lesions of the uterine cervix.

\section{LIMITATIONS}

Hormone-related changes uncommonly pose problems in diagnosis. Due to educational backwardness and sociocultural hesitations facing many patients at our place they arrive very late at medical facilities. If these obstacles can be removed and patients come early then many neoplastic conditions can be diagnosed at early stages.

\section{REFERENCES}

1. F. Nausheen, J. Iqbal, F. A. Bhatti, A. T. Khan, and S. Sheikh, "Hysterectomy: the patient's perspective," Annals of Gynecology, vol. 10, pp. 339-341, 2004.

2. J. M. Wu, M. E. Wechter, E. J. Geller, T. V. Nguyen, and G. Visco, "Hysterectomy rates in the United States, 2003," Obstetrics and Gynecology, vol. 110, no. 5, pp. 1091-1095, 2007.

3. Thompson, and John A.Rock. Chapters 1, 13 and 27 in Telinde's Operative Gynecology. J.B. Lippincott Company, Philadelphia, Pennsylvania, 7th edition; 1992; p1-10, 297-99,663-68.

4. Sunita Malik, Jai Bhagwan Sharma, Nirmal Gulati, and K.Jain. A Clinico- Pathological Study of Adenomyosis. J Obstet Gynecol India 1992; 42: p234-38.

5. Priya Bhide and Amarnath Bhide. Uterine Adenomyosis. J Obstet Gynecol India 1994; 44(4): p612-15.

6. Gautam Allahbadia, Vijay Ambiye, and Pratibha Vaidya. Study of Vaginal Hysterectomy in Cases Other Than Done for Prolapse. J Obstet Gynecol India 1991; 41(4): p543-46.

7. Kasturi Lal, and Yudhister Vir Gupta. Adenomyosis- A Clinical and Pathological Appraisal. J Obstet Gynecol India 1981; 31: p173-76.

8. Ajmera Sachin K, Mettler L, and Jonat W. Operative spectrum of hysterectomy in a German university hospital. J Obstet Gynecol India 2006; 56(1): p59-63.

9. Stewart FC and Arti P. The Frequency of Uterine Leiomyomas. Am J Clin Pathol 1990; 94: p435-38.

10. Veena S Naik, Jyoti D Rege, and Kusum D Jashnani. Pathology of Genital Tract in Postmenopausal Bleeding. Bombay hospital journal-Original/Research. www.bhj.org/journal/2005_4703_july/ html/original- pathology-250.htm-17k.

11. Roopam Kalrā et al. A Clinicopathological Study of Adenomyosis Uteri (106 Cases). J Obstet Gynecol India 1983; 33: p512-14.

12. John J. Molitor. Adenomyosis: A Clinical and pathologic appraisal. Am J Obstet Gynecol 1971; 110(2): p275-84.

13. Henry Annan et al. Myomectomy: Uterus saving surgery for fibroids. Obstet Gynaec Today 2005; 10(8): p456-58.

14. Jacobson GF, Shaber RE, Armstrong MA, et al. Changes in rates of hysterectomy and uterine conserving procedures for treatment of uterine leiomyoma. Am J Obstet Gynecol 2007; 196(6): p601.e1601.e6.

15. M. L. Solapurkar. Histopathology of Uterine Cervix in Malignant and Benign Lesions. J Obstet Gynecol India 1985; 35(3): p933-37.

16. Nalini Gupta, Anshu Awasthi, Arvind Rajwanshi, and Malhotra Sarla. A Case Report. Fine Needle Aspiration Cytology of Low Grade Endometrial Stromal Sarcoma. Acta Cytol 2007; 51: p461-63.

\section{Source of Support: Nil. Conflict of Interest: None Declared.}

Copyright: (c) the author(s) and publisher. IJMRP is an official publication of Ibn Sina Academy of Medieval Medicine \& Sciences, registered in 2001 under Indian Trusts Act, 1882.

This is an open access article distributed under the terms of the Creative Commons Attribution Non-commercial License, which permits unrestricted non-commercial use, distribution, and reproduction in any medium, provided the original work is properly cited.

Cite this article as: Ankur Gupta, Sangita Sehgal , Ajay yadav, Vinod Kumar. Histopathological Spectrum of Uterus and Cervix in Hysterectomy Specimens. Int J Med Res Prof. 2016; 2(3):136-39. 